\title{
A bioabsorbable (polyglactin), nonrestrictive, external sheath inhibits porcine saphenous vein graft thickening
}

Jamie Y. Jeremy, PhD
Richard Bulbulia, FRCS
Jason L. Johnson, MSc $^{\text {a }}$
Patricia Gadsdon, BSc
Vikram Vijayan, FRCS
Nilima Shukla, PhD
Frank C. T. Smith, FRCS
Gianni D. Angelini, FRCS

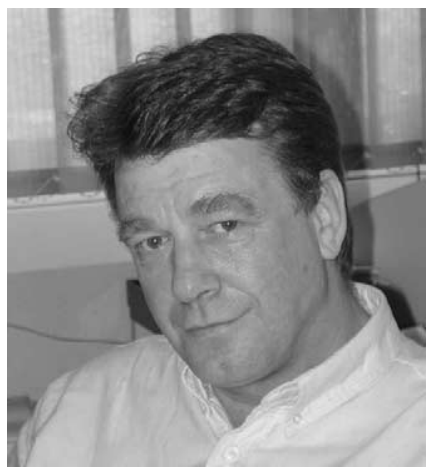

J. Y. Jeremy
From The Bristol Heart Institute ${ }^{\mathrm{a}}$ and Vascular Studies Unit, Bristol Royal Infirmary, ${ }^{\text {b }}$ University of Bristol, Bristol, United Kingdom, and School of Biomolecular Sciences, ${ }^{\mathrm{c}}$ Liverpool John Moores University, Liverpool, United Kingdom.

Supported by The Garfield Weston Foundation and the British Heart Foundation.

Received for publication June 18, 2003; revisions requested Sept 19, 2003; accepted for publication Sept 23, 2003.

Address for reprints: Dr Jamie Y Jeremy, Bristol Heart Institute, Bristol Royal Infirmary, University of Bristol, Bristol BS2 8HW, United Kingdom (E-mail: j.y.jeremy @ bris.ac.uk)

J Thorac Cardiovasc Surg 2004;127: $1766-72$

$0022-5223 / \$ 30.00$

Copyright (๑) 2004 by The American Association for Thoracic Surgery

doi:10.1016/j.jtcvs.2003.09.054
Objective: External, nonrestrictive, macro-porous polyester stents prevent neointima formation in porcine vein grafts and have been proposed as a therapeutic approach to the prevention of late vein graft failure. These stents are nonbiodegradable and therefore may promote long-term foreign body problems including infection and inflammation. The effect of external macro-porous biodegradable (polyglactin) sheaths on neointimal and medial thickening in porcine vein grafts was therefore investigated.

Methods: Bilateral saphenous vein-carotid artery interposition grafting was performed in white Landrace pigs $(n=8)$ with external placement of polyglactin (Vicryl) sheaths ( $8 \mathrm{~mm}$ in diameter) on 1 side, with the contralateral side acting as a control. One month after surgery, grafts were explanted and wall dimensions measured on histological sections using computer-aided planimetry, and an immunocytochemical appraisal was carried out.

Results: All grafts were patent at explantation. Polyglactin sheaths significantly reduced intimal thickness, medial thickness, and the percentage of proliferating cells compared with unsheathed controls. There was a pronounced accumulation of macrophages, giant cells, endothelial cells, and microvessels within and surrounding the biodegradable sheath compared with controls.

Conclusions: A nonrestrictive, biodegradable (polyglactin), external sheath reduces medial and intimal thickening in experimental saphenous vein grafts, possibly through inflammatory cell-mediated angiogenesis. If subsequent long-term studies confirm preservation of this beneficial effect, once the sheath biodegrades, this approach may have an advantage over the permanent polyester stent when applied clinically.

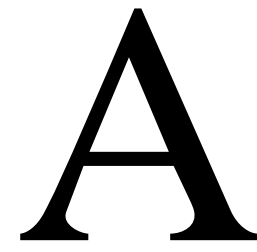
utologous saphenous vein remains widely used in coronary artery bypass surgery ${ }^{1}$ and is the graft material of choice in lower limb arterial reconstructive surgery. ${ }^{2}$ However, the effectiveness of saphenous vein grafts is limited by patency rates approaching $50 \%$ at 10 years after surgery. ${ }^{1,3}$ Although $10 \%$ to $15 \%$ of grafts fail due to early thrombotic occlusion, the majority occlude due to progressive medial thickening and neointimal hyperplasia and subsequent superimposed atherosclerosis. ${ }^{1-3}$ Furthermore, there is no intervention apart from aggressive lipid lowering ${ }^{4}$ that has proved successful in ameliorating late vein graft failure. ${ }^{5}$

It has previously been demonstrated that placement of an external, macro-porous, nonrestrictive, polyester stent reduces neointima formation in porcine vein grafts. ${ }^{6}$ 
However, significant concerns remain as to the application of such external stents in arteriovenous bypass grafts in humans. Long-term vein graft support with polyester may elicit foreign body and mechanical complications, known to be associated with the implantation of prosthetic material. ${ }^{7-9}$ Furthermore, because neointima formation in vein grafts occurs within 1 month after implantation, long-term support may not be necessary. ${ }^{10}$ A possible means of avoiding these complications is to employ an absorbable external sheath that remains intact for at least 1 month but then is subsequently biodegraded. One material that fulfils these criteria is polyglactin 910 (Vicryl; Ethicon Inc, Somerville, NJ), a copolymer of glycoside and L-lactide and absorbable material used as suture material in herniorraphy and ophthalmic surgery and in protecting traumatized solid intra-abdominal organs. ${ }^{11-13}$ Absorption has been reported to be complete between 56 and 70 days postimplantation. ${ }^{11-13} \mathrm{We}$ therefore investigated the effect of a polyglactin, nonrestrictive $(8 \mathrm{~mm})$, external sheath on neointima formation in a porcine model of saphenous vein carotid artery interposition grafting.

\section{Materials and Methods}

\section{Surgical Procedures}

Studies were performed using white Landrace pigs ( $\mathrm{n}=8$, weight 22-28 kg), which received humane care in accordance with the Home Office Animals (Scientific Procedures) Act of 1986. ${ }^{14}$ Approval for the study was also obtained from the Internal Review Board of the University of Bristol. Animals were subjected to premedication, anesthesia, and autologous saphenous vein into common carotid interposition bypass grafting by a modification of the method described previously. ${ }^{6}$ In brief, $10-\mathrm{cm}$ segments of long saphenous vein were dissected using a no-touch technique and stored in an isoosmotic sodium chloride solution $(0.9 \mathrm{~g} / \mathrm{L})$ containing $2 \mathrm{IU} / \mathrm{mL}$ heparin and $50 \mu \mathrm{g} / \mathrm{mL}$ glyceryltrinitrate at room temperature $\left(23^{\circ} \mathrm{C}\right)$ until needed. Both common carotid arteries were exposed and vascular clamps applied proximally and distally after intravenous injection of heparin $(2 \mathrm{IU} / \mathrm{mL})$. On each side, 3-cm segments of artery were excised and both cut ends beveled to $45^{\circ}$. Appropriate lengths of reversed saphenous vein were similarly beveled and anastomosed end-to-end with the arteries using continuous 7-0 Prolene sutures (Ethicon Inc, Somerville, NJ). Sheets of Vicryl mesh (Ethicon Inc) were fashioned into 8-mm diameter tubes (sheaths) with continuous 5-0 Vicryl sutures (Figure 1) and applied to 1 graft as an external support, covering both anastomoses and $1 \mathrm{~cm}$ of proximal and distal common carotid artery. The contralateral grafts remained unstented as controls. Use of distal or proximal portions of vein and the sides externally stented were randomized. Neck and leg wounds were closed in layers and the animals recovered and fed a normal chow diet.

After 4 weeks the animals were reanesthetized and the grafts explanted and pressure-fixed ex vivo at $100 \mathrm{~mm} \mathrm{Hg}$ with a $6 \%$ paraformaldehyde in phosphate-buffered saline solution (PBS) containing $2 \%$ sucrose for 10 minutes. The grafts were then postfixed in the same solution for 24 hours before being transferred to PBS and processed for wax embedding. Transverse sections (5

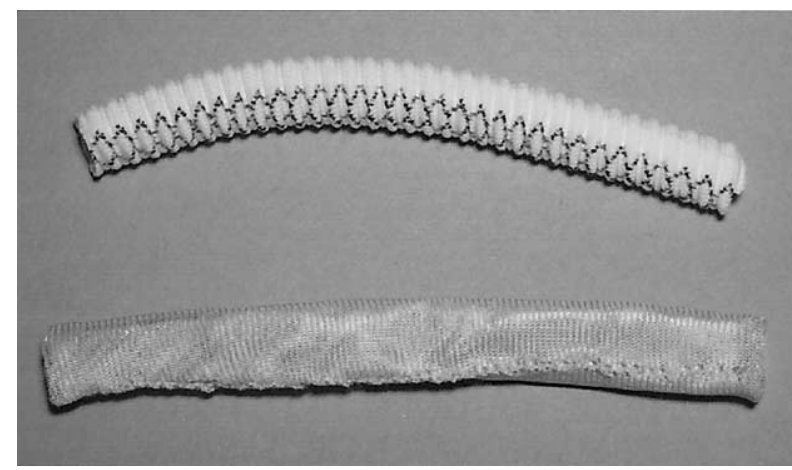

Figure 1. The polyglactin (Vicryl) sheath (below) compared with the external polyester stent (above), both of which are $8 \mathrm{~mm}$ in diameter. Previous studies have established that the polyester stent inhibits saphenous vein graft thickening in the pig model.

$\mu \mathrm{m})$ were taken from 6 equidistant points along each graft, mounted on glass slides, and stained with Alcian blue Miller's elastic stain and van Gieson (EVG) stain and hematoxylin and eosin (H\&E) staining.

\section{Morphometric Analysis}

Vessel wall dimensions were measured by computer-aided planimetry with an Olympus BH-2 microscope with a color video camera system and Microscale TM/TC image analysis system (Digithurst Ltd, Royston, Herts, UK).

The area enclosed by the endothelium and the internal elastic lamina defined the intima, and the area between the internal and external elastic lamina defined the media. Luminal encroachment was defined as the percentage of the area enclosed by the internal elastic lamina occupied by the intima. Luminal, intimal, and medial perimeters and areas were computed using the luminal boundary and internal and external elastic laminae as delimiters, and mean values were then calculated for all sections from the same graft. Average intimal, medial, and total vessel wall thickness was derived from the area and perimeter data for 5 sections from each graft, assuming that the sections consisted of circular profiles, which was valid because the tissues were fixed at normal perfusion pressures.

\section{Immunocytochemistry}

Sections were dewaxed, rehydrated, and treated with hydrogen peroxide in methanol to remove endogenous peroxidase and sections treated with horse serum were diluted 1 in 3 with Trisbuffered saline (TBS), $\mathrm{pH} 7.4$, then drained and incubated overnight at $4{ }^{\circ} \mathrm{C}$ with the following antibodies: (1) for vascular smooth muscle cells (VSMCs): monoclonal mouse anti-alpha actin clone 1A4 (Dako, High Wycombe, UK) diluted 1:500 with TBS. For macrophage staining, sections were treated with trypsin and then incubated with mouse monoclonal MAC387 (Dako) diluted 1:50 with TBS. For proliferating cell nuclear antigen (PCNA), sections were microwaved in $10 \mathrm{mmol} / \mathrm{L}$ citrate buffer, $\mathrm{pH} 6$, quenched in 1 in 3 horse serum in TBS, and then incubated with PCNA antibody diluted 1 in 75 overnight at $4^{\circ} \mathrm{C}$. After incubation with primary antibodies, sections were washed and treated with 1 in 400 
a)

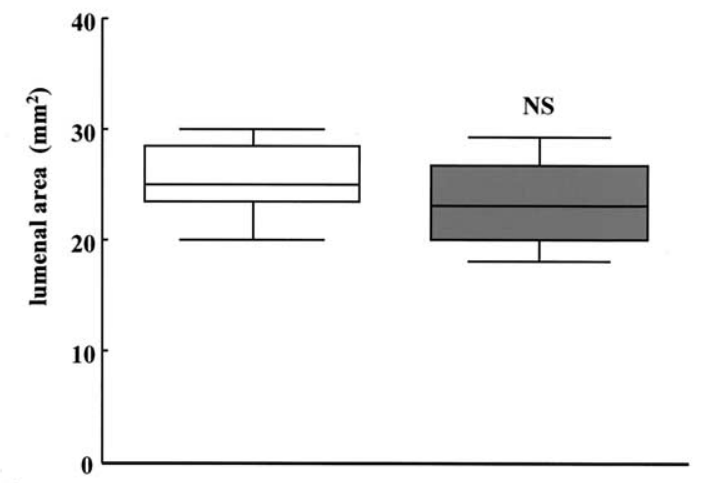

c)

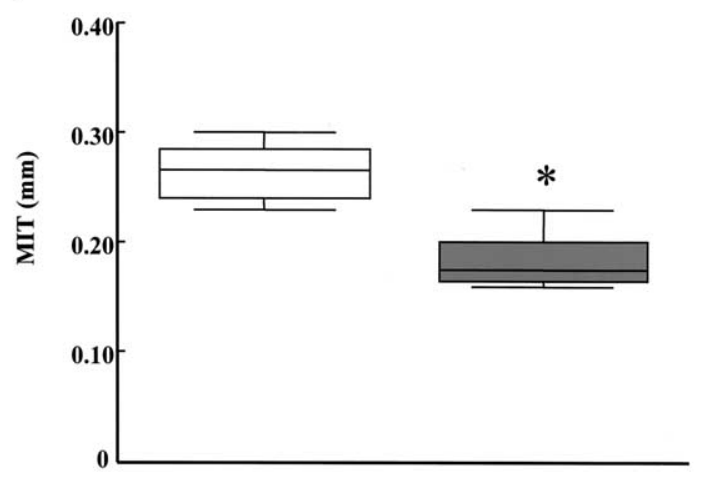

b)

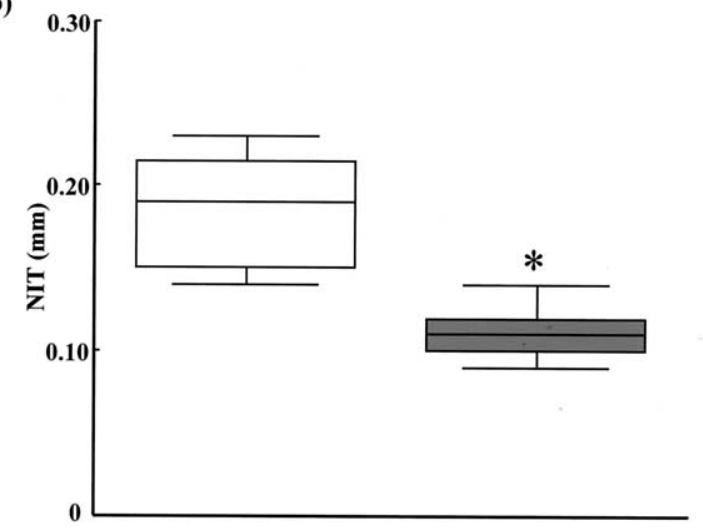

d)

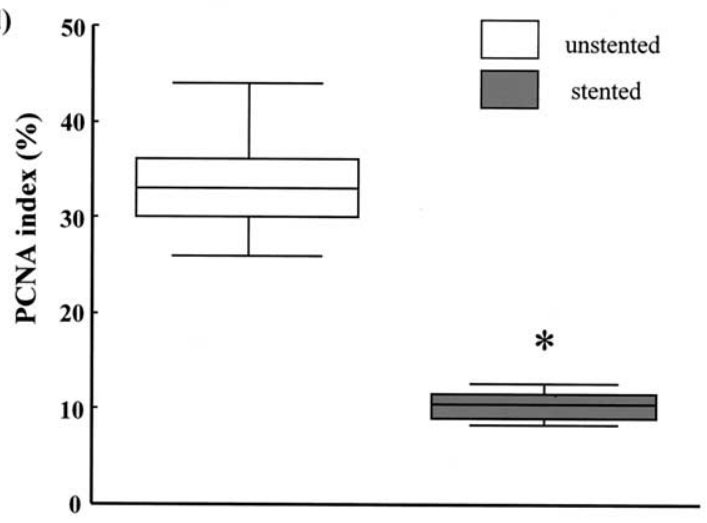

Figure 2. Planimetric analysis of saphenous vein grafts fitted with polyglactin external sheaths 1 month after implantation. a, Luminal area (LA); b, neointimal thickness (NT); c, medial thickness (MIT); and d, \% cells positively stained for PCNA (PCNA index). Data are expressed as box and whisker plots, $\mathrm{n}=8$. Asterisk denotes statistical significance when comparing sheathed with unsheathed saphenous vein grafts (Wilcoxon matched-pair signedrank test with a Bonferroni adjustment).

biotinylated goat anti-mouse immunoglobulin and then with streptavidin biotin complex/horseradish peroxidase (Strept/ABC/ HRPO [Dako]). For endothelial cells, sections were incubated with horse serum diluted 1 in 3 with $20 \mathrm{mmol} / \mathrm{L}$ Hepes buffer, $\mathrm{pH}$ 7.5, drained, and incubated overnight at $4{ }^{\circ} \mathrm{C}$ with biotinylated antiGriffonia Simplicifolia, lectin 1 isolectin B4 (Vector Laboratories, Peterborough, UK) diluted to $15 \mu \mathrm{g} / \mathrm{mL}$ with $20 \mathrm{mmol} / \mathrm{L}$ Hepes buffer, $\mathrm{pH} 7.5$, again followed by Strept/ABC/HRPO (Dako). Visualization was achieved using 3,3'-diaminobenzidine, and then after counterstaining with diluted hematoxylin, sections were dehydrated and mounted. The PCNA sections were counterstained with diluted $\mathrm{H} \& \mathrm{E}$ before dehydration and mounting. For dual labeling of lectin and PCNA, sections were treated as above for endothelial cells and followed by microwave treatment and incubation in PCNA at 1 in 75 overnight. They were then treated with goat anti-mouse immunoglobulin G (Dako) at 1 in 50 followed by alkaline phosphatase anti-alkaline phosphatase (Dako) and visualized using Vector Blue kit (Vector Laboratories). The sections were counterstained using nuclear fast red.

The total number of cells positive for PCNA was counted in 4 fields at $\times 40$ magnification, which abutted the lumen and included the neointima and inner media. Five sections per graft were as- sessed. The number of PCNA-positive cells was expressed as a percentage of the total cell number (PCNA index).

\section{Data Analysis and Statistics}

Data were collated and analyzed using Microsoft Excel (Microsoft Corporation, Redmond, Wash) and nonparametric statistical analysis carried out using an Intercooled Stata 8 statistics package (Stata Corporation, College Station, Tex). Although data did not appear to be skewed, Barlett's test for equality of variance (a necessary assumption for a 1-way analysis of variance [ANOVA]) was significant, indicating that nonparametric methods of analysis was required. Thus, values are expressed as median and interquartile ranges and graphically as whisker box plots. The KruskalWallis test, a nonparametric version of ANOVA, was applied and then the Wilcoxon matched-pair signed-rank test was used to test for statistical significance.

\section{Results}

All data cited in this section are the medians (25th and 75th interquartile ranges) (Figure 2). All grafts were patent at explantation (1 month after implantation). Vicryl sheath 


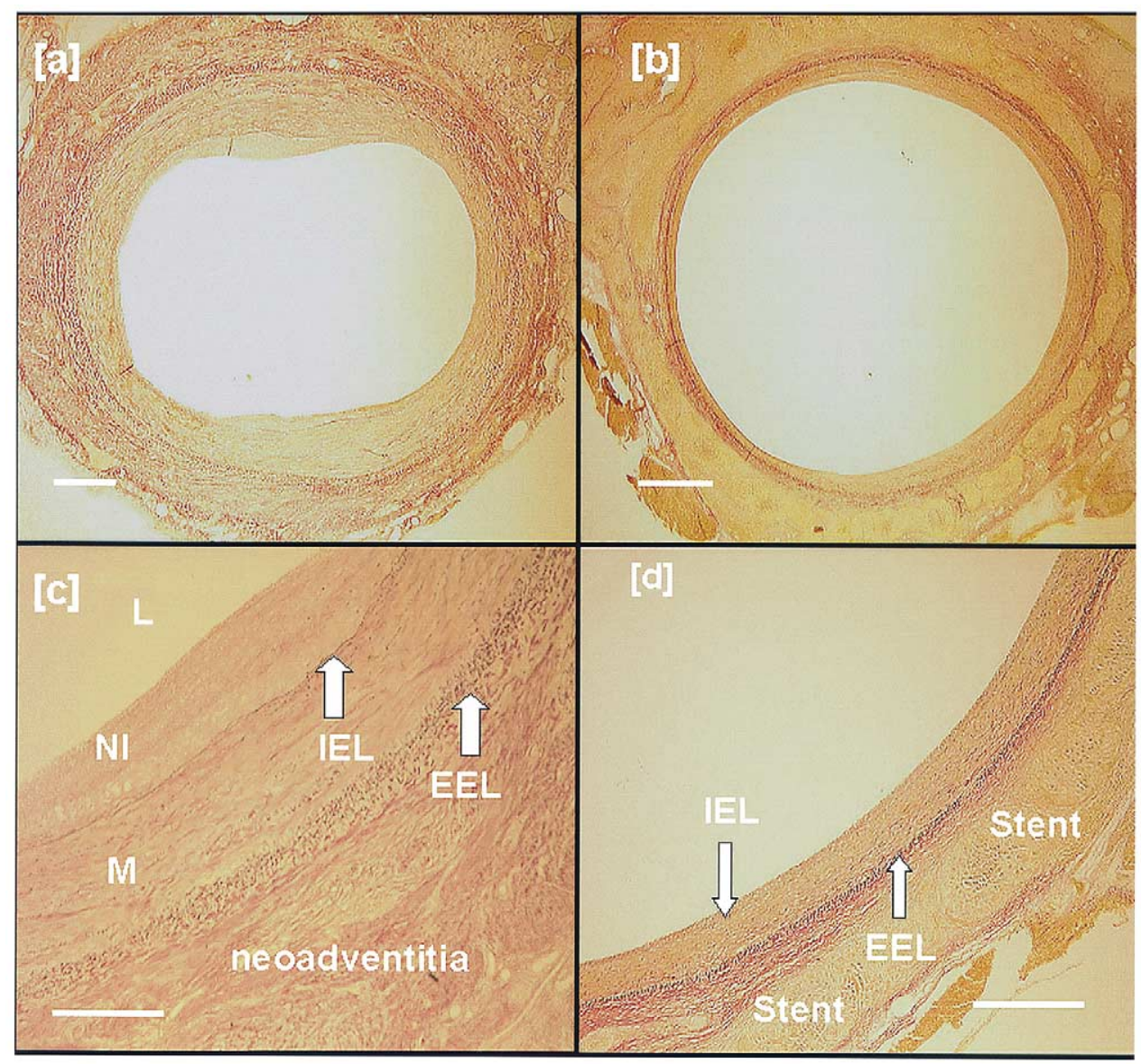

Figure 3. Representative photomicrographs of H\&E-stained transverse sections of a control vein graft (a and c) and a vein graft fitted with a polyglactin external nonrestrictive sheath (b and d). The scale bar in panels (a) and (b) represent $1 \mathrm{~mm}$ and the scale bar in panels (c) and (d) represents $250 \mu \mathrm{m}$. L, Lumen; NI, neointima; M, media; NA, neoadventitia; IEL, internal elastic lamina; EEL, external elastic lamina.

material was still clearly visible in the outer adventitial region (Figures 3 and 4). In vein grafts fitted with a Vicryl sheath there was a statistically significant decrease in neointimal thickness $(0.11$ [0.07-0.12] mm) compared with unsheathed grafts $(0.19$ [0.15-0.215] $\mathrm{mm})$ and in medial thickness $(0.175 \pm 0.165-0.2] \mathrm{mm})$ compared with unsheathed controls $(0.285$ [0.26-0.305] mm) (Figures 2 and $3)$. There was no statistically significant difference in the lumenal areas when comparing sheathed with unsheathed controls (Figure 2). In vein grafts fitted with a Vicryl sheath there was a statistically significant decrease in cells that were positively stained for PCNA in the medial/intimal region $(9.85 \%$ [8.9\%-11.6\%]) compared with unsheathed vein grafts (33\% [30\%-39\%]) (Figure 2). The diameter of the sheathed grafts from the external elastic lamina to the lumenal endothelium was significantly greater in unsheathed grafts $(7.9$ [7.7-8.1] mm) compared with grafts fitted with a Vicryl sheath $(6.1$ [5.9-6.3] mm). It is notable that the diameter of the sheathed graft was markedly less than the diameter of the sheath (ie, $8 \mathrm{~mm}$ ), indicating that the sheath has not become tight fitting at 1 month.

Immunocytochemical studies indicated that the space between graft and sheath had become organized into a neoadventitia that contained microvessels, particularly in the region closer to the stent (Figure 4,a). There were large numbers of macrophages within and around the sheath (Figure $4, b$ ) as well as giant cells (Figure 4, d). The neoadventitia and the sheath material contained large numbers of both endothelial cells (Figure 4,c) and VSMCs (Figure 4, d). Microvessels in the inner region of the sheath appeared to be connected with those immediately outside it (Figure 4, d). Cells within the sheath material displayed a high degree of PCNA positivity, indicating active proliferative processes (angiogenesis) occurring within the sheath.

\section{Discussion}

The present study demonstrates that placement of an external, macro-porous, loose-fitting, polyglactin sheath inhibits 


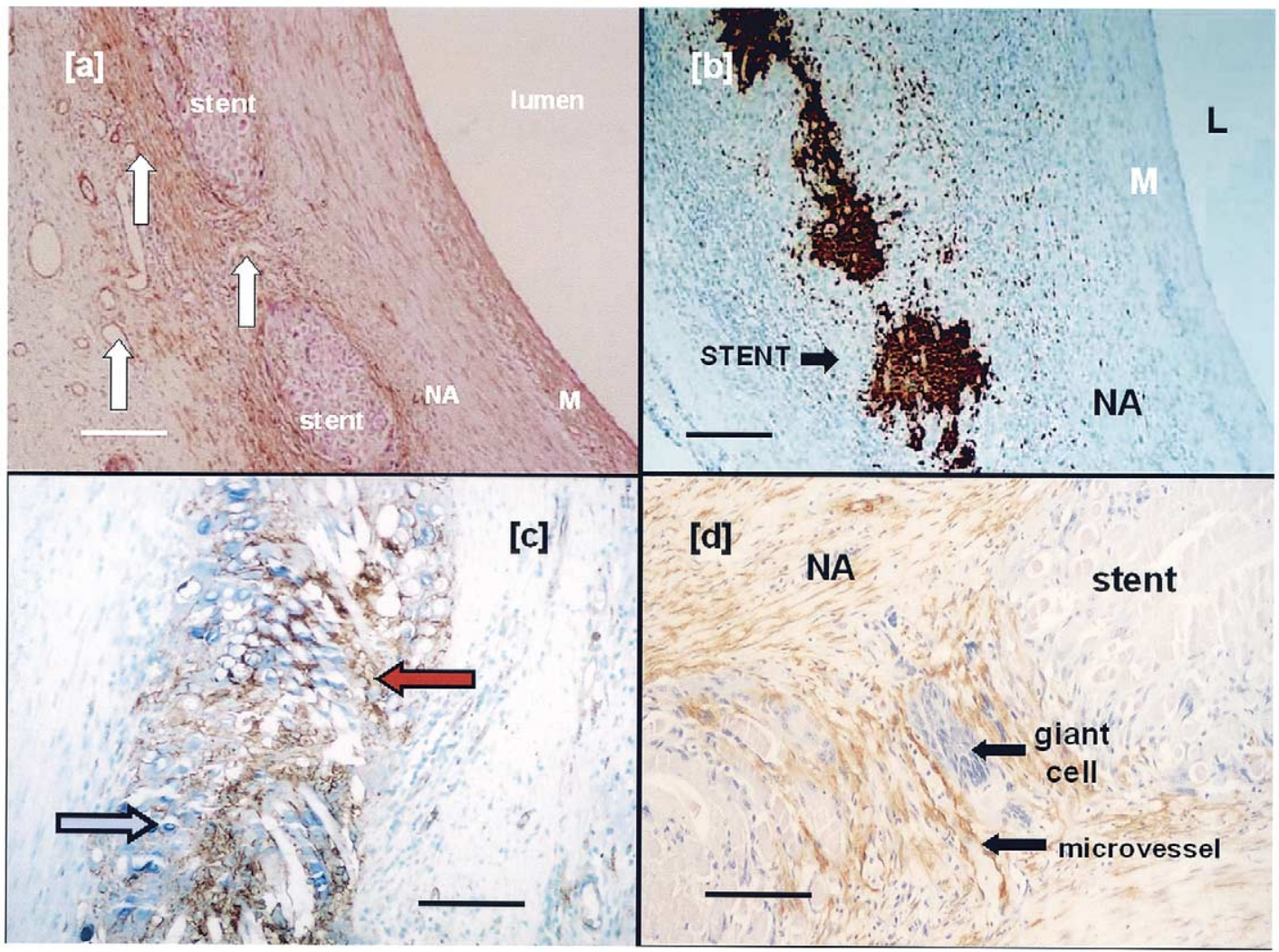

Figure 4. Photomicrographs of pig vein grafts fitted with an external polyglactin stent demonstrating the following. a, The distribution of microvessels within the biodegradable sheath and immediately outside it indicated with white arrows. Scale bar represents $100 \mu \mathrm{m}$. b, Immunostaining for MAC387 showing large numbers of macrophages (dark brown) associated with the sheath material as well as in the neoadventitia (NA) with few, if any, macrophages present in the media (M), however. Scale bar represents $\mathbf{1 0 0} \mu \mathrm{m}$. c, Dual labeling of endothelial cells (b/ue arrow) and cells positive for PCNA (red arrow) within the sheath material. Scale bar $=50 \mu \mathrm{m}$. d, Immunostaining for $\alpha$-actin (brown) and giant cells (purple). Scale bar $=50 \mu \mathrm{m}$. Note the microvessel passing from inside to the outside of the sheath in close proximity to the giant cell and VSMCs that have infiltrated the sheath.

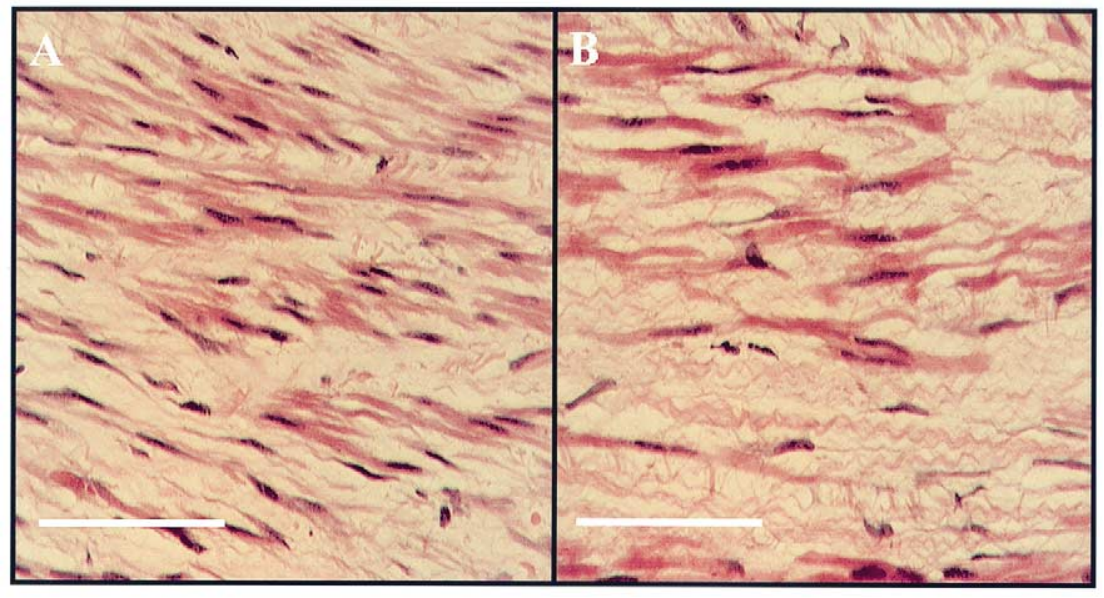

Figure 5. Comparison of EVG staining of the medial region of pig saphenous vein grafts: (A) fitted with an external Vicryl sheath and (B) unsheathed controls 1 month after graft implantation. Scale bar $=20 \mu \mathrm{m}$. There was no indication of edema, disorganization, or inflammation in the medial region of the externally sheathed graft demonstrating that medial quality is maintained or improved by the sheath. 
neointimal and medial thickening in porcine vein grafts to the same degree as a nonbiodegradable polyester external stent of identical diameter. ${ }^{6}$ External sheaths made of biodegradable materials could therefore be used clinically to prevent saphenous vein graft thickening and reduce graft failure following arterial reconstructive surgery.

For the external polyester stent to prevent neointimal thickening, it had to be loose-fitting and macro-porous. ${ }^{14}$ The polyglactin sheath employed in the present study fulfilled both criteria. Tight-fitting polyester stents $(5 \mathrm{~mm})$, which prevented early distension of the vein graft, did not prevent neointima formation or graft thickening ${ }^{15}$ whereas 8 -mm stents were optimally effective in the pig. ${ }^{16}$ Tightfitting biodegradable sheaths prevented disorganization, edema, and neutrophil accumulation ${ }^{17-19}$ (Figure 5) but not neointimal hyperplasia. ${ }^{20}$ With the 8 -mm polyester stent, the space between the graft and the stent becomes organized into a cell-rich "neoadventitia," abundant with microvessels. ${ }^{6,14}$ Within this "neovasa vasorum," these microvessels infiltrate through the spaces within the stent and were continuous with the vasculature outside the stent. ${ }^{6,14}$ With a restrictive stent, not surprisingly, this microvessel-rich neoadventitia was absent. ${ }^{15,16}$

It was proposed, therefore, that the loose-fitting external polyester stent allows for the development and promotion of a neoadventitia in the space between the graft and the stent. In turn, this allows for the development of microvessels that may obviate graft wall hyperplasia through the prevention of graft hypoxia. ${ }^{5}$ In the present study, the polyglactin sheath was also $8 \mathrm{~mm}$ in diameter (and therefore loosefitting when placed around the vein graft) and also promoted the formation of microvessels, particularly in and around the sheath material. This consolidates the possible importance of initial nonrestriction in promoting angiogenesis and microvessel formation and hence prevention of neointima formation in vein grafts.

Porosity was also found to be important in mediating the effect of the polyester external stent. Polytetrafluoroethylene (micro-porous) stents (also $8 \mathrm{~mm}$ in diameter) not only promoted neointimal and medial thickening but also prevented microvessel formation. ${ }^{14}$ Porosity appears to be crucial since it allows the microvessels that form in the neoadventitia to connect with the vasculature outside the stent allowing a fully integrated blood flow to the graft. This nonporous stent, by preventing this connection, effectively negates the positive effect of angiogenesis. ${ }^{14}$ The polyglactin sheath studied here is also highly porous, allowing the free infiltration of microvessels while still allowing the formation of a microvessel-rich neoadventitia.

Another striking facet of the polyglactin sheath was that macrophages and giant cells, as well as endothelial cells, VSMCs, and microvessels, had accumulated within and around the material. Because macrophages release a battery of factors that promote angiogenesis, ${ }^{21,22}$ it is reasonable to suggest that the enhanced microvessel formation observed with loose-fitting external stents is initiated and maintained by the accumulation of inflammatory cells in this region. As VSMCs were seen in large numbers in and around the polyglactin sheath, it is also reasonable to postulate that the resident intrasheath macrophages set up a gradient of higher concentrations of chemotactic substances within the stent relative to that within the graft wall. This, in turn, would promote the migration of VSMCs out toward the sheath and therefore prevent neointima formation. It is perhaps important to note that the distance between the graft and the sheath (and the macrophages associated with it) may itself be crucial to the impact of the external sheath. Indeed, Bambang and colleagues ${ }^{20}$ found in vein grafts with tight fitting Vicryl sheaths that neointimal hyperplasia was not inhibited and there was an accumulation of macrophages in the medial region. This close proximity of macrophages, through the release of remodeling factors, may elicit the undesirable effect of VSMC proliferation in the media/ intima and explain, in part, why loose-fitting stents and/or sheaths are effective.

It is also likely that the sheath has a direct physical impact on graft biology. Although initially the graft does not interact with the loose-fitting sheath (the sheath is $8 \mathrm{~mm}$ in diameter and the graft $5 \mathrm{~mm}$ when fully distended), the formation of a neoadventitia renders the graft physically continuous with the medial/intimal component of the graft. At 1 month, the external elastic lamina is still some distance from the sheath, which is separated from it by the adventitia, indicating that the sheath has not become constrictive, a facet that has been shown to promote neointima formation.

The present study also demonstrates that the Vicryl sheath was still present at 1 month after implantation, which is consistent with a previous report that Vicryl meshes are completely absorbed in vivo after 5 months. ${ }^{23}$ Thus, longerterm studies (over 6 months) are required to determine whether positive effect of the Vicryl sheath persists after its complete absorption.

From a clinical perspective, the use of a polyester external stent may significantly increase the risk of graft infection, a serious complication of peripheral arterial reconstructive surgery. ${ }^{7-9}$ Indeed, there is evidence that use of biodegradable materials has a lower incidence of surgical wound infection. ${ }^{24-27}$ In the long term, the nonbiodegradable polyester stent may elicit other problems, in particular chronic inflammation and fibrosis. Employment of a biodegradable external sheath may avoid these recognized and potential problems while achieving the primary objective of preventing graft thickening. Additionally, this external Vicryl sheath may represent a means of delivering drugs (eg, losartan and paclitaxel) that prevent graft thickening locally to the graft. Thus, at implantation, the space between the 
graft and the sheath could be filled with a pluronic gel containing appropriate drugs that may augment the inhibition of graft thickening and associated pathology. Loosefitting, highly porous, biodegradable, external vascular sheaths may therefore represent a safer and more applicable prosthesis for use in arterial reconstructive surgery. Further longer-term studies are required to consolidate these hypotheses.

We are grateful to Dr Christine Rogers for advice on statistical analyses.

\section{References}

1. Motwani JG, Topol EJ. Aortocoronary saphenous vein graft disease. Pathogenesis, predisposition and prevention. Circulation. 1998;97: 916-31.

2. Jackson MR, Belott TP, Dickeson T, Kaiser WJ, Modrall JG, Valentine RJ, et al. The consequences of a failed femoropopliteal bypass grafting: comparison of a saphenous vein and PTFE graft. J Vasc Surg. 2000;32:498-505.

3. Varty K, Allen KE, Bell PRF, London NJM. Infra-inguinal vein graft stenosis. Br J Surg. 1993;80:825-33.

4. Campeau L. Lipid lowering and coronary bypass graft surgery. Curr Opin Cardiol. 2000;15:395-9.

5. Vijayan V, Smith FC, Angelini GD, Bulbulia RA, Jeremy JY. External supports and the prevention of neointima formation in vein grafts. Eur J Vasc Endovasc Surg. 2002;24:13-22.

6. Mehta D, George SJ, Jeremy JY, Izzat MB, Southgate KM, Bryan AJ, et al. External stenting reduces long-term medial and neointimal thickening and platelet derived growth factor expression in a pig model of arteriovenous bypass grafting. Nat Med. 1998;4:235-9.

7. Bunt TJ. Synthetic vascular graft infections. I. Graft infections. Surgery. 1983;93:733-46.

8. Edwards WH Jr, Martin RS 3rd, Jenkins JM, Edwards WH Sr, Mulherin JL Jr. Primary graft infections. J Vasc Surg. 1987;6:235-9.

9. Murphy GJ, Pararajasingam R, Nasim A, Dennis MJ, Sayers RD. Methicillin-resistant staphylococcus aureus infection in vascular surgical patients. Ann R Coll Surg Engl. 2001;83:158-63.

10. Jacobson LE, Kirton OC, Gomez GA. The use of an absorbable mesh wrap in the management of major liver injuries. Surgery. 1992;111: 455-61.

11. Lee SS, Cheng CL, Yu DS, Chang SY, Ma CP. Vicryl mesh for repair of severely injured kidneys: an experimental study. J Trauma. 1993; 34:406-10.

12. Tribble CG, Joob AW, Barone GW, Rodgers BM. A new technique for wrapping the injured spleen with polyglactin mesh. Am Surg. 1987; 53:661-3.

13. Dasdia T, Bazzaco S, Bottero L, Buffa R, Ferrero S, Campanelli G, et al. Organ culture in 3-dimensional matrix: in vitro model for evaluating biological compliance of synthetic meshes for abdominal wall repair. J Biomed Mater Res. 1998;43:204-9.

14. George SJ, Izzat MB, Gadsdon P, Johnson JL, Yim AP, Wan S, et al. Macro-porosity is necessary for the reduction of neointimal and medial thickening by external stenting of porcine saphenous vein bypass grafts. Atherosclerosis. 2001;155:329-36.

15. Violaris A, Newby AC, Angelini GD. Effects of external stenting on wall thickening in arteriovenous bypass grafts. Ann Thorac Surg. 1993;55:667-71.

16. Izzat MB, Mehta D, Bryan AJ, Newby AC, Angelini GD. Influence of external stent size on early medial and neointimal thickening in a pig model of saphenous vein bypass grafting. Circulation. 1996;94:1741-5.

17. Zweep HP, Satoh S, van der Lei B, Hinrichs WL, Dijk F, Feijen J, Wildevuur CR. Autologous vein supported with a biodegradable prosthesis for arterial grafting. Ann Thorac Surg. 1993;55:427-33.

18. Zweep HP, Satoh S, van der Lei B, Hinrichs WL, Feijen J, Wildevuur CR. Degradation of a supporting prosthesis can optimize arterialization of autologous veins. Ann Thorac Surg. 1993;56:1117-22.

19. Hinrichs WL, Zweep HP, Satoh S, Feijen J, Wildevuur CR. Supporting, microporous, elastomeric, degradable prostheses to improve the arterialization of autologous vein grafts. Biomaterials. 1994;15:83-91.

20. Bambang LS, Moczar M, Lecerf L, Loisance D. External biodegradable supporting conduit protects endothelium in vein graft in arterial interposition. Int J Artif Organs. 1997;20:397-406.

21. Goronzy JJ, Weyand CM. Cytokines in giant cell arteritis. Cleve Clin J Med. 2002;69:91-4.

22. Weyand CM, Goronzy JJ. Pathogenic mechanisms in giant cell arteritis. Cleve Clin J Med. 2002;69:28-32.

23. Meddings RN, Carachi R, Gorham S, French DA. A new bioprosthesis in large abdominal wall defects. J Pediatr Surg. 1993;28:660-3.

24. Kapadia CR, Mann JB, McGeehan D, Jose Biglin JE, Waxman BP, Dudley HA. Behaviour of synthetic absorbable sutures with and without synergistic enteric infection. Eur Surg Res. 1983;15:67-72.

25. Paterson-Brown S, Cheslyn-Curtis S, Biglin J, Dye J, Easmon CS, Dudley HA. Suture materials in contaminated wounds: a detailed comparison of a new suture with those currently in use. Br J Surg. 1987;74:734-5.

26. Demirer S, Gecim IE, Aydinuraz K, Ataoglu H, Yerdel MA, Kuterdem E. Affinity of Staphylococcus epidermidis to various prosthetic graft materials. J Surg Res. 2001;99:70-4.

27. Franklin ME Jr, Gonzalez JJ Jr, Michaelson RP, Glass JL, Chock DA. Preliminary experience with new bioactive prosthetic material for repair of hernias in infected fields. Hernia. 2002;6:171-4. 